\title{
Regeneracionismo, sanidad y discurso racial: Felipe Ovilo Canales y la confluencia entre España y Marruecos a finales del siglo XIX
}

\author{
Francisco Javier Martínez Antonio \\ Investigador contratado «Juan de la Cierva» Instituto de Historia, CCHS, CSIC. \\ franciscojavier_martinez@cchs.csic.es
}

Dynamis

[0211-9536] 2009; 29: 73-96

Fecha de recepción: 5 de marzo de 2008

Fecha de aceptación: 4 de diciembre de 2008

SUMARIO: 1.-Introducción. 2.-La confluencia hispano-marroquí. 3.—La visión marroquí de Felipe Ovilo Canales y sus trasuntos españoles. 4.-Una trayectoria de reformismo sanitario entre España y Marruecos. 5.-El discurso racial de Felipe Ovilo: la centralidad de los «moros». 6.-Conclusión.

RESUMEN: El médico militar Felipe Ovilo Canales fue una figura destacada y representativa de los proyectos coloniales españoles en Marruecos durante la Restauración. A diferencia de las iniciativas de otros países europeos, dichos proyectos se orientaron a impulsar y controlar el proceso de reformas del Estado marroquí. En este trabajo se analizará cómo, en el plano de las ideas políticas, esta estrategia llevó a Ovilo a formular un discurso de confluencia entre España y Marruecos; en el ámbito sanitario, a tener un papel protagonista en el Consejo Sanitario de Tánger y en la Escuela de Medicina militar de Tánger; $y$, finalmente, en su discurso científico, a adoptar una perspectiva racial sobre los «moros» basada en consideraciones históricas y morales, más que biológicas.

PALABRAS CLAVE: Felipe Ovilo Canales, relaciones hispano-marroquíes, Restauración, salud pública, discurso racial, moros.

KEY WORDS: Felipe Ovilo Canales, Spanish-Moroccan relationships, Restauration, public health, racial discourse, moors. 


\section{Introducción $\left(^{*}\right)$}

Cuando el Médico Mayor de Sanidad Militar Felipe Ovilo Canales (Segovia 1850- Madrid 1909) fue destinado por primera vez a la Legación diplomática de Tánger, en septiembre de 1877, hacía tiempo que el triunfalismo suscitado en España por la Guerra de África se había apagado ${ }^{1}$. Ovilo venía de pasar seis años de servicio en Cuba, donde la sublevación independentista iniciada en 1868 con el "grito de Baire» había obligado a emplear decenas de miles de soldados en una guerra que cerraría en falso el general Martínez Campos. No fue éste el único conflicto armado de la época, ya que, durante el breve periodo republicano que precedió a la restauración de Alfonso XII, continuó el desarrollo de la Tercera Guerra Carlista, iniciada en 1872, y comenzó el levantamiento cantonalista ${ }^{2}$. Para Marruecos, tampoco había sido un periodo fácil. Mohammed IV comenzó su reinado con una derrota militar contra España que, aparte del coste material y humano, se tradujo en ciertas concesiones territoriales (ampliación de los campos exteriores de Ceuta y Melilla; adjudicación legal del enclave de Santa Cruz de la Mar Pequeña) y en el pago de una cuantiosa indemnización económica financiada en parte a través de la intervención española de las aduanas portuarias $^{3}$. Hasta su muerte en 1873, el Sultán luchó en vano por frenar el debilitamiento del Estado marroquí frente a los periódicos levantamientos internos y la creciente influencia extranjera ${ }^{4}$.

(*) Este trabajo ha sido realizado gracias a una beca postdoctoral de la AECI, Programa III-B, a una beca Juan de la Cierva del MICINN, convocatoria 2007, y al proyecto de investigación HUM2006-12278-C03-01 dirigido por Ricardo Campos Marín.

1. Sobre el fervor patriótico asociado a la Guerra de África, ver García Balañá, Alberto. Patria, plebe y política en la España isabelina: la guerra de África en Cataluña (1859-1860). In: Martín Corrales, Eloy ed. Marruecos y el colonialismo español (1859-1912). De la guerra de África a la «penetración pacífica». Barcelona: Bellaterra; 2002, p. 13-78.

2. Sobre ese periodo, ver Tomás Villarroya, Joaquín, coord. La era isabelina y el sexenio democrático (1834-1874). Historia de España Menéndez Pidal dirigida por José María Jover Zamora. Tomo XXXIV. Madrid: Espasa-Calpe; 1988; Fontana, Josep. La época del liberalismo. Historia de España dirigida por Josep Fontana y Ramón Villares. Vol. 6, Barcelona: Crítica/Marcial Pons, 2007.

3. Rodríguez Esteller, Omar. La intervención española de las aduanas marroquíes (1862-1885). In: Martín Corrales, n. 1, p. 79-131.

4. Para una perspectiva general sobre este periodo, ver Miège, Jean-Louis. Le Maroc et l'Europe, 1830-1894. Vol. IV, Paris: PUF; 1963; Julien, Charles-André. Le Maroc face aux impérialismes, 1415-1956. Paris: Editions J.A.; 1978; Pennell, Charles Richard. Morocco since 1830. A History. 
En estas circunstancias, las relaciones hispano-marroquíes a comienzos de los reinados de Alfonso XII y Hassan I ofrecían para España un perfil ambiguo. Por una parte, las posibilidades de intervención al otro lado del Estrecho eran mayores que en décadas anteriores, en el sentido de que ya no era preciso realizar un despliegue militar y diplomático de tanta envergadura como había sido necesario en la Guerra de África. Un Marruecos más frágil aparecía por primera vez como horizonte colonial capaz de ofrecer una alternativa viable al retroceso de la presencia española en Cuba. Pero, al mismo tiempo, era patente la debilidad de los proyectos españoles en Marruecos frente a los de otras potencias europeas, ya que cualquier iniciativa exitosa de parte de España tendía, en la práctica, a traducirse en mayores ventajas para dichas potencias, como ya había sucedido a raíz del conflicto de 1859-60. En nuestra opinión, fue esta disyuntiva la que otorgó al colonialismo español en Marruecos a finales del siglo XIX su carácter particular en comparación con el de otros países europeos.

En la dura competición por asegurarse la posición preferente en el futuro reparto del Imperio Xerifiano, considerado como inevitable a medio plazo, una potencia como Francia desplegó una mezcla de expansionismo militar y «penetración pacífica» que pretendía debilitar el Estado marroquí y colocarlo en situación de dependencia «civilizatoria» a la manera argelina ${ }^{5}$. Por su parte, Gran Bretaña reconoció la soberanía del Sultán más allá del alcance real y efectivo de la misma, con el fin de asegurarse un trato comercial y diplomático prioritario y, al tiempo, cerrar las puertas a la injerencia de otros países en un punto vital para su entramado imperial ${ }^{6}$. En el caso de España, la debilidad frente a estas potencias dio lugar a una estrategia basada en el apoyo al proceso de reformas administrativas, económicas y militares de Marruecos. Se

London: Hurst and Company; 2000; Morales Lezcano, Víctor. Historia de Marruecos. Madrid: La Esfera de los Libros; 2006.

5. Sobre la actuación francesa en Marruecos a finales del siglo XIX, ver, entre otros, Miège, n. 4; Burke, Edmund III. Prelude to Protectorate in Morocco. Precolonial protest and resistance, 1860-1912. Chicago/London: University of Chicago Press; 1976; Abdelhamid, Smaili Moulay. Les années terribles du Maroc oriental. 2 vols., Oujda: BMFI; 1996.

6. Sobre la actuación británica en Marruecos antes del Protectorado, ver, entre otros, Parsons. F.V. The origins of the Morocco question, 1880-1900. London: Duckworth; 1976; Bendaoud, Abdelwahed; Maniar, Mohammed, eds. Tanger 1800-1956. Contribution à I'histoire recente du Maroc. Rabat: Éditions Arabo-africaines; 1981; Brett, Michael. Great Britain and Southern Morocco in the Nineteenth Century. Journal of North African Studies. 1997; 2 (2): 1-10. 
renunciaba con ello, en principio, a perseguir un dominio colonial sensu stricto del país, a cambio de obtener el protagonismo principal en sus transformaciones internas.

El principal objetivo del presente trabajo es analizar esta particular estrategia colonial española en el Marruecos de finales del siglo XIX a través de uno de sus más destacados, aunque al mismo tiempo menos conocidos, representantes: el doctor Felipe Ovilo Canales ${ }^{7}$. Como veremos, tanto en el ámbito general de la política, como en el especializado de la sanidad y la medicina, Ovilo defendió las reformas en el vecino país africano no sólo como medio preferente de aumentar la influencia española en el mismo, sino también de fortalecer la propia sociedad peninsular según la línea marcada por el movimiento regeneracionista del que formaba parte. En este sentido, nuestro trabajo mostrará asimismo la confluencia entre sus discursos políticos y científico-sanitarios sobre España y Marruecos, confluencia que surgió del paralelismo entre su posición institucional, social e incluso geográfica a ambos lados del Estrecho. Como en el caso de otros protagonistas españoles de la época, dicho paralelismo dio lugar a una mirada sobre Marruecos y los «moros» en la que la percepción de superioridad coexistió, más o menos problemáticamente, con una conciencia de afinidad y proximidad ${ }^{8}$.

\section{La confluencia hispano-marroquí}

España actuó con progresiva cautela en Marruecos después de la Guerra de África. A raíz del desenlace del conflicto se fue instalando la convicción de que, por culpa de medidas demasiado agresivas, Francia o Gran Bretaña podían hacerse con el control del país vecino, lo que supondría

7. Una aproximación a la bibliografía existente sobre el doctor Felipe Ovilo Canales, en Martínez Antonio, Francisco Javier. Intimidades de Marruecos. Miradas y reflexiones de médicos españoles sobre la realidad marroquí. Madrid: Miraguano Ed., 2009, p. 22-30.

8. El enfoque biográfico que forma la base de este trabajo permite, en nuestra opinión, percibir e indagar las conexiones entre diferentes discursos y prácticas que normalmente tienden a analizarse de forma separada. Sin dejar, en este caso, de resaltar la relevancia de Ovilo como personaje histórico frente al olvido a que ha sido relegado. Sobre las posibilidades y limitaciones de las biografías científicas, ver Dossier «Biografías médicas, una reflexión historiográfica». Asclepio. 2005; 57 (1); Shortland, Michael; Yeo, Richard. Telling Lives in Science. Essays on Scientific Biography. Cambridge: Cambridge University Press; 1996. 
una amenaza directa para la integridad peninsular. La visión del doctor Felipe Ovilo Canales sobre las relaciones hispano-marroquíes se perfiló a partir de la conciencia de este riesgo fundamental. Así, Ovilo afirmaba ya en su primera obra general Estudios políticos y sociales sobre Marruecos (1881) que,

«España, que se encuentra más interesada que ninguna otra [nación] en el imperio marroquí [...], debe aprovechar las ocasiones que se le presenten de aumentar su poder en ese país [...]. De no hacerlo así, naciones más vigorosas o más prácticas se encargarán de realizar la misión que por tantos motivos estamos llamados a llevar a feliz término. Si por desdicha esto aconteciese, bastaría dirigir una mirada al mapa de Europa [...] para comprender los peligros que nos amenazarían, y en los cuales hasta nuestra nacionalidad pudiera verse comprometida ${ }^{9}$.

Esta opinión coincidía con la del establishment político de la Restauración y con la de otros miembros del recién constituido movimiento africanista y aparecería también en Estado actual de Marruecos (1888) y en Intimidades de Marruecos (1894), lo que nos indica su importancia fundamental en el pensamiento de Ovilo y subraya la continuidad de éste a lo largo de todo el periodo ${ }^{10}$. Independientemente de otras consideraciones, dicha opinión revelaba la percepción, más bien indeseada, de una confluencia o un entrelazamiento entre los destinos históricos hispano-marroquíes, consecuencia de la analogía esencial entre sus respectivas posiciones de debilidad en la escena internacional. Analogía no quería decir igualdad, ya que, para Ovilo, España tenía al otro lado del Estrecho un vecino más débil, «a merced de las rapacidades del ambicioso»; por las consecuencias directas que esta vulnerabilidad podía tener, estaba sobradamente justificado el derecho «que tenemos para intervenir amistosamente en sus asuntos» ${ }^{11}$. Marruecos era en definitiva «un pueblo

9. Ovilo, Felipe. Estudios sociales y políticos sobre Marruecos. Madrid: [s.n.]; 1881, p. 18.

10. Fernández Rodríguez, Manuel. España y Marruecos en los primeros años de la Restauración (1875-1894). Madrid: CSIC; 1985; Pedraz Marcos, Azucena. Quimeras de África. La Sociedad Española de Africanistas y Colonistas. El colonialismo español a finales del siglo XIX. Madrid: Polifemo; 2000; Akmir, Youssef. Marruecos y la política exterior española durante los primeros gobiernos de la Restauración 1874-1887. Hesperis-Tamuda. 2000; 38: 89-104.

11. Ovilo, Felipe. Estado actual de Marruecos. Madrid: Librería de Fernando Fé; 1888, p. 40. 
menor de edad» y había que actuar con él como «con un amigo desvalido: protegerle siempre que se pueda hacer sin perjuicio de España» ${ }^{12}$.

Esta última observación reflejaba, no obstante, las limitaciones de la superioridad española y explicaba, según Ovilo, que España hubiera optado por la defensa del entonces denominado statu quo marroquí, por el que se habían «sacrificado muchos intereses» ${ }^{13}$. Así, España era uno de «los pueblos que tenían interés en que no desapareciera Marruecos» y, gracias al apoyó prestado al Sultán «a costa de no pequeños sacrificios, no se derrumbó el imperio» ${ }^{14}$. Era necesario hacer "concesiones en Marruecos para sostener el poder y el prestigio del Sultán que, desapareciendo, traería el caos al Mogreb y una serie de complicaciones gravísimas para la paz europea» ${ }^{15}$. En definitiva, España tenía que «guardar una circunspección en Marruecos, que la ha de obligar a grandes sacrificios», en contraste con otros países europeos «que no temen crear conflictos y a quienes preocupan poco ciertas consideraciones» ${ }^{16}$. No obstante, esta forma de actuar no se debía sólo a la impotencia frente a las presiones de otros países extranjeros, sino que Ovilo podía lamentarse igualmente de «la pasión, que en España se sobrepone siempre a la idea y que envenena las causas más justas [...] nada nos importa, si batimos al adversario, herir, pisotear y enlodecer la madre común de todos: la patria bendita» ${ }^{17}$. Frente a esto, era necesario prestar la máxima atención a los asuntos marroquíes y actuar en ellos con la mayor prudencia y consenso, ya que, en su opinión, un «pueblo que no se preocupa sino de vivir al día, y pierde un tiempo precioso en discusiones [...] estériles [...], pierde sus energías y no tarda en alzarse sobre él el látigo de la servidumbre» ${ }^{18}$.

Todo ello se traducía en que España no podía ni debía desplegar una acción estrictamente colonialista en Marruecos. En este mismo sentido, una figura tan representativa como Joaquín Costa propugnaba para ese país una «misión de regeneración» bastante más modesta en sus medios y en sus expectativas que la «misión civilizadora» defendida entonces por Francia y Gran Bretaña, tanto para Marruecos como para otros escenarios de su

\footnotetext{
12. Ovilo, Felipe. Intimidades de Marruecos. Madrid: Librería de Fernando Fé; 1894, p. 67-68.

13. Ovilo, n. 12, p. 18

14. Ovilo, n. 11, p. 11, 15.

15. Ovilo, n. 12, p. 15, 17.

16. Ovilo, n. 11, p. 37-38.

17. Ovilo, n. 12, p. 59-60.

18. Ovilo, n. 12, p. 69.
} 
expansión colonial ${ }^{19}$. En nuestra opinión, la concepción del movimiento africanista sobre lo que España debía hacer en Marruecos descansaba más en el ejemplo del programa regeneracionista español que en los discursos de franca superioridad de tipo colonialista o civilizador. De ahí que, para Ovilo, España tuviera como principal objetivo colaborar en las reformas del Estado marroquí, y hacerlo no por la fuerza militar, ni en nombre de la superioridad moral, sino modestamente dando «ejemplo, no creando conflictos, ni dificultades» ${ }^{20}$. En su opinión, esta actitud constituía el núcleo de la política marroquí desplegada por el Ministro de Estado, Segismundo Moret, entre 1885 y 1888, porque las reformas que el político gaditano había impulsado «no perturban en nada la organización política y administrativa de Marruecos, [...] ni han causado ni pueden causar recelos en las suspicaces potencias extranjeras» ${ }^{21}$.

\section{La visión marroquí de Felipe Ovilo Canales y sus trasuntos españoles}

La percepción de una confluencia hispano-marroquí explicaría, en nuestra opinión, que la visión de Marruecos por parte de africanistas de la Restauración como Ovilo recurriera a la proyección implícita de los esquemas empleados para analizar la sociedad española, entre otros, del concepto decisivo de regeneración. Una proyección que fue posible, a su vez, por la existencia de una analogía esencial en la situación profesional, social, política o institucional de los actores españoles en ambos países ${ }^{22}$. En el caso de Ovilo, comenzaremos el análisis de dicha analogía señalando su adscripción socio-política a la oligarquía española y a su equivalente marroquí ${ }^{23}$. Una vocación reformista que inclinó sus simpatías políticas hacia

19. López García, Bernabé. La ciencia como instrumento de la acción colonial en Marruecos. Contextos y polémicas. In: De Felipe, Helena; López Ocón, Leoncio; Marín, Manuela eds. Ángel Cabrera: ciencia y proyecto colonial en Marruecos. Madrid: CSIC; 2004, p. 15.

20. Ovilo, n. 11, p. 29-30.

21. Ovilo, n. 11, p. 32.

22. Esta analogía constituiría un caso específicamente español de «circulación» de personal especializado en Marruecos en comparación con la existente en escenarios coloniales de otras potencias europeas. Sobre el concepto de circulación, ver Haynes, Douglas. Imperial Medicine. Patrick Manson and the Conquest of Tropical Disease. Philadelphia: University of Pennsylvania Press; 2001; Raj, Kapil. Relocating Modern Science. Circulation and the Construction of Scientific Knowledge in South Asia and Europe. Oxford: Permanent Black; 2006.

23. Martínez Antonio, n. 7, p. 23. 
el Partido Liberal, sus inquietudes sociales e intelectuales hacia el regeneracionismo y su trayectoria profesional hacia Marruecos, no impidió que Ovilo formara parte de las élites de la España de la Restauración y de los círculos de poder próximos a la Monarquía ${ }^{24}$. Fue amigo de Segismundo Moret y del padre José Lerchundi y trabajó directamente para altos jefes militares como el General Martínez Campos. Fue integrante activo de diversas embajadas españolas al Sultán, socio correspondiente de la Real Academia de Historia y articulista en diversos periódicos de ámbito nacional. Participó activamente en la vida intelectual del Ateneo de Madrid y en la constitución del movimiento africanista y recibió menciones del gobierno y condecoraciones de la reina regente María Cristina ${ }^{25}$.

Cuando Ovilo se desplazó a Marruecos, se movió en círculos análogos a los que había frecuentado en España, aunque no existiera ninguna relación formal entre unos y otros. En sus escritos e informes administrativos que fue elaborando en los años siguientes, Ovilo describió sus encuentros con el sultán Hassan I, por quien fue recibido al menos en tres ocasiones en Rabat, Tánger y Fez, y a quien encontró como parte de la embajada española a Marrakesh en 1894. Además de tener contactos puntuales con el Sultán y con sus visires, Ovilo mantuvo estrecha relación con altos funcionarios como los naibs (delegados del Sultán en Tánger para tratar con los cónsules extranjeros) Mohammed Bargach y Mohammed Torres, con notables como el xerif de Uazzan, con miembros destacados de la comunidad judía tangerina, así como con los cónsules extranjeros acreditados en la ciudad, tanto por razón de sus obligaciones profesionales, como con ocasión de bailes, banquetes o recepciones. Finalmente, Ovilo trabajó directamente para diversos jefes de la Legación de Tánger y embajadores españoles a la corte xerifiana y se relacionó con los miembros más influyentes de la colonia española. En suma, Ovilo se posicionó en Marruecos dentro de una élite de tendencia reformista, como había hecho anteriormente en España.

Esta analogía en su posición social a ambos lados del Estrecho influyó en que la visión de Ovilo sobre Marruecos fuera esencialmente una imagen deformada, aunque lejos de resultar irreconocible, de la realidad administrativa y socio-política española de su época. El viaje a Marruecos era, a fin de cuentas, un viaje cercano y este hecho se reflejó tanto en aspectos

24. Laredo, Isaac. Memorias de un viejo tangerino. Rabat: Éditions La Porte; 1994, p. 166.

25. Laredo, n. 24, p. 166-175; Martínez Antonio, n. 7. 
formales, como de contenido de sus diversas obras de temática marroquí. Por ejemplo, en Estado actual de Marruecos (1888), al narrar el momento de su llegada a Tánger dos años antes, Ovilo empleaba significativamente la tercera persona, como única forma de transmitir una sensación de extrañeza en un escenario que, por todo lo demás, le resultaba bastante familiar ${ }^{26}$. De hecho, tanto el viaje en barco como la visión de la ciudad habían perdido su romanticismo de antaño: el trayecto azaroso, la alcazaba, las casas blancas y las mujeres con velo habían sido sustituidas por vapores, faros, cables de telégrafo, ventanas, ropas europeas, turistas y periódicos ${ }^{27}$. La modestia del desplazamiento (entendido en términos culturales) se revelaba explícitamente en el siguiente comentario:

«a las pasaderas fondas de antaño han reemplazado unos magníficos establecimientos, que por su lujo, comodidad y trato superan a muchos de los de su género reputados en Madrid como de primer orden» ${ }^{28}$.

Ovilo veía, por tanto, en Tánger un trasunto de su Madrid de procedencia, no sólo al nivel literal del alojamiento, sino por extensión en lo que se refiere al lugar central que ocupaba la ciudad en la administración y la sociedad marroquíes. Como en el caso de Madrid, lo que sucedía en Tánger era un anticipo de lo que iba a suceder en el resto del país y así Ovilo podía afirmar, en relación con los cambios que encontraba entre su primera y su segunda estancia, que «la costa está hoy como Tánger hace quince años; si las cosas siguen de igual modo, la costa dentro de poco tiempo será lo que Tánger hoy», una transformación que se notaba incluso «en algunas poblaciones del interior» ${ }^{29}$. Del mismo modo, fue su posición geográfica e institucional en Tánger la que permitiría a Ovilo desplazarse por buena parte del territorio en misiones de diverso carácter que le dieron la oportunidad de tener una visión de conjunto sobre la realidad marroquí. Entre otros lugares, Ovilo conoció Larache y Rabat en 1888, Fez y Uazzan en 1891, Mazagán y Marrakech en 1894.

26. Ovilo comenzaba dicha narración de la siguiente manera: «el que visitó a Marruecos, y muy especialmente a Tánger, hace diez años, y hoy nuevamente pisa aquella tierra, nota cambios y encuentra diferencias que desde luego llaman su atención». Ovilo, n. 11, p. 13.

27. Ovilo, n. 11, p. 13-14.

28. Ovilo, n. 11, p. 14.

29. Ovilo, n. 11, p. 14 
Estratégicamente emplazado en la atalaya tangerina, puerta y centro del país, Ovilo podía observar todavía a Marruecos como una entidad unitaria, aunque indudablemente afectada por graves problemas. La esencia y el resumen de todos ellos era que el Imperio Xerifiano se encontraba «en decadencia»y, «como todos los países musulmanes, tiende a su desaparición en el mapa político de los pueblos» ${ }^{30}$. Era doloroso constatar cómo «aquel temido y floreciente estado musulmán que feneció en Granada; aquel pueblo hispano-árabe [...] no han dejado herederos de sus glorias» ${ }^{31}$. El gobierno no sabía «hacerse respetar» ni trataba de «mejorar el estado de sus súbditos»; el potencial agrícola estaba desaprovechado, se restringía la exportación de los «mejores productos»y «no se eleva por su extenso territorio el humo de ninguna fábrica»; la administración era «nula», los impuestos, excesivos, la justicia, «viciada o corrompida»; la marina, casi inexistente y «proscritos todos los progresos y adelantos de la ciencia moderna» ${ }^{32}$. En definitiva, se trataba de un pueblo «cuyos carcomidos cimientos amenazan pronta ruina, y que parece próximo a desaparecer» ${ }^{33}$.

En esta situación, la unidad de Marruecos se sostenía precariamente gracias a la figura del Sultán, «clave que sujeta aquel complicado organismo» ${ }^{34}$. Pero el Sultán gobernaba de forma autocrática y personalista, lo que, además de privar de competencias reales a la mayoría de sus ministros, hacía que el nepotismo y la corrupción minaran el funcionamiento de la administración. Para Ovilo, desde el Majzén central hasta los caídes y bajás, «intermediarios entre el pueblo y el poder supremo», dicha administración se regía por «la más profunda inmoralidad»: el gobierno no pedía «cuentas a sus delegados, ínterin éstos correspondan con regalos y atenciones a la superioridad, y esta misma conducta se sigue por los jefes inmediatos con sus inferiores» ${ }^{35}$. La concentración de poder político, militar y administrativo explicaba «el lujo» de la vida de caídes y bajás, ya que «cobran los impuestos, imponen las multas, se incautan de los bienes de los que mueren sin hijos y herederos directos y [...] ordenan las prisiones y castigos a los habitantes de sus respectivas provincias» ${ }^{36}$. Aunque Hassan I había empezado una

30. Ovilo, n. 9, p. 2.

31. Ovilo, n. 11, p. 3-4.

32. Ovilo, n. 9, p. 1-2.

33. Ovilo, n. 11, p. 1-2.

34. Ovilo, n. 12, p. 15

35. Ovilo, n. 9, p. 80-81.

36. Ovilo, n. 9, p. 80. 
«obra de regeneración [...] y se observa que en los últimos nombramientos de las autoridades empieza por atender a los méritos personales, sobre la intriga, antes dueña y soberana», lo cierto es que «sólo el tiempo, con la instrucción y el mayor trato con los extranjeros, podrá introducir en el Mogreb cambios y modificaciones que, impuestos de repente, darían origen a trastornos sin límites» ${ }^{37}$.

Dado que «su poder efectivo [...], como Rey, alcanza a una muy pequeña parte del país», el Sultán debía valerse sobre todo del prestigio que le otorgaba su condición de Comendador de los creyentes ${ }^{38}$. Según Ovilo, el «fanatismo religioso [...] es la fuerza que mantiene unidos a los marroquíes y merced a la cual el Sultán, sin un gran ejército, sin la complicada constitución de los pueblos civilizados, sostiene su inmenso poder en el Mogreb Al-Aksa» ${ }^{39}$. A esto se añadía el hecho de que el Sultán obtuviera también poder por su condición de jefe último de las cofradías religiosas, «asociaciones secretas» que «reemplazan en Marruecos a los partidos políticos de por acá» y que, por esta razón, constituían «el único elemento para que no desaparezca la unidad nacional $[\ldots]_{\gg}{ }^{40}$. A todos estos factores que acabamos de señalar, había que añadir también la acusada heterogeneidad racial del país, cuyas «cinco razas distintas de opuestas tendencias y costumbres» (árabes, bereberes, judíos, moros y negros) y con idiomas diferentes, se encargaba de «impedir la constitución de una nacionalidad fuerte y respetable» ${ }^{41}$.

Dentro de esta amalgama, los «moros», especialmente los de las ciudades eran, para Ovilo, «los verdaderos amos de Marruecos» ${ }^{42}$. Por su parte, los árabes, muy reducidos en número desde los tiempos de la conquista, se caracterizaban por defender un «régimen aristocrático y teocrático» en el que se «reconoce y respeta la nobleza religiosa hereditaria y, entre ella, elige sus autoridades políticas, sus jefes militares y sus administradores» ${ }^{43}$. Con todo, eran los bereberes el grupo étnico más numeroso, constituyendo en torno a «la mitad de la población del imperio marroquí» ${ }^{44}$. La mayor parte

\footnotetext{
37. Ovilo, n. 11, p. 29-30.

38. Ovilo, n. 12, p. 18.

39. Ovilo, n. 11, p. 10

40. Ovilo, n. 12, p. 14-15.

41. Ovilo, n. 9, p. 49.

42. Ovilo, n. 9, p. 59-61.

43. Ovilo, n. 9, p. 54-57.

44. Ovilo, n. 9, p. 2.
} 
de ellos sólo respetaba nominalmente la autoridad del Sultán. En contraposición con los árabes, defendían un «régimen democrático» y llegaban a ser, por ello, «más socialistas que los rusos» ${ }^{45}$. No obstante, las relaciones entre tribus se caracterizaban por la división y las luchas continuas, lo que permitía al Sultán explotarlas para mantener su poder. También había en Marruecos población de raza negra, que vivía en régimen de esclavitud. No obstante, ésta no era «tan rígida ni tan cruel como ha sido en otros países», y la «benignidad» en el trato se manifestaba en que, una vez libres, eran considerados como los demás musulmanes y «pueden aspirar a todos los cargos del imperio» ${ }^{46}$. Finalmente, completaban el mosaico racial los judíos, la mayoría descendientes de los expulsados de España y Portugal. A cambio de una tolerancia religiosa «que no hallaron en pueblos civilizados y que profesan la religión más humana y más caritativa», los judíos debían tolerar «denigrantes vejaciones» ${ }^{47}$. No obstante, un pequeño porcentaje, aprovechándose del derecho de protección asociado a la penetración europea, «han hecho algunas fortunas [...] censuradas hasta por los mismos hebreos honrados y trabajadores» ${ }^{48}$. Como todos aquellos "que no les vejaron ni se sirvieron de ellos para nada incorrecto», Ovilo no tenía «la más leve queja de estos hombres», pero lamentaba que estuvieran tomando partido abiertamente por Francia y Gran Bretaña «sin reflexionar que, en caso de no realizar sus proyectos su [nación] protectora, están perdidos para siempre» 49 .

Finalmente, la falta de cohesión del país no era sólo étnico-lingüística sino también territorial, social e incluso religiosa. Así, el sostén del Estado marroquí, en términos políticos, militares o económicos, lo constituían «los habitantes de las llanuras, los más sufridos y los que han de soportar todas las cargas colectivas» ${ }^{50}$. Pero las tierras sometidas plenamente a la autoridad del Sultán, lo que se denominaba bled el-makhzen, no alcanzaban a «la quinta parte del imperio» ${ }^{51}$. Por ello, el Sultán debía «transigir y adular en cierto modo a los caciques de las regiones, señores feudales, cuya influencia en sus

45. Ovilo, n. 9, p. 1-13.

46. Ovilo, n. 9, p. 64

47. Ovilo, n. 12, p. 10

48. Ovilo, n. 11, p. 21

49. Ovilo, n. 11, p. 21-23

50. Ovilo, n. 12, p. 18-19.

51. Ovilo, n. 12, p. 13-14 
tierras es harto poderosa» ${ }^{52}$. También debía satisfacer las exigencias de las cofradías religiosas, que llegaban a constituir una especie de «principados» independientes como sucedía en el caso de Uazzan. Finalmente, debía «estar constantemente vigilando el estado de las revueltas y levantiscas kábilas, que se sublevan bajo cualquier pretexto, pero siempre con el motivo real de no pagar los tributos que las correspondan $[\mathrm{sic}] »{ }^{53}$.

En los diversos aspectos de esta visión suya sobre Marruecos, Ovilo intentó enfatizar de forma consciente la distancia socio-cultural de la realidad marroquí respecto a sus términos de comparación españoles/europeos. El uso de términos como fanatismo, salvajismo o inmoralidad y de adjetivos como viciada, miserable o corrompida contribuía a que los destinatarios de sus escritos descartaran una posible identificación con la situación al otro lado del Estrecho. Pero el propio Ovilo no podía sustraerse a la existencia de un alto grado de paralelismo con la realidad española, de forma que para su análisis de la situación de Marruecos le resultaron útiles conceptos como rey, unidad nacional, regiones, caciques, socialismo, anarquía o partidos políticos, que se empleaban corrientemente en la discusión política y sociológica peninsular. Esta batería terminológica ya estaba presente en sus primeras publicaciones, pero, posteriormente, dio paso a críticas explícitas de la sociedad española, como en Intimidades de Marruecos, obra en la que Ovilo reflexionaba sobre las tendencias cainitas de los españoles y sus partidos políticos y sobre el «indiferentismo» y la pasividad de España ante sus desafíos más importantes ${ }^{54}$.

No obstante, fue en su última monografía, La decadencia del ejército. Estudio de higiene militar (1899), publicada después de su segundo y último destino en Cuba y después del desastre del 98, cuando Ovilo aplicó abiertamente a España análisis que anteriormente había reservado para Marruecos. Esto empezaba ya por el propio título, con el concepto de decadencia del que tanto hablarían los intelectuales y escritores del 98 y que seguiría constituyendo un tema de debate durante décadas. La decadencia española, dibujada por Ovilo para el caso del ejército pero aplicable en el fondo a toda la sociedad, se parecía en muchos de sus elementos a la que había considerado como característica del Imperio Xerifiano. Por ejemplo, un aspecto clave de la misma eran las continuas luchas y conflictos inter- 
nos, ya que «desde principios de siglo no hemos tenido tranquilidad; nos hemos visto devorados por guerras que nos han empobrecido $[\ldots]{ }_{\gg}{ }^{5}$. Por otra parte, Ovilo descubría en ese momento una fatal heterogeneidad en la sociedad española, que habría contribuido decisivamente a los enfrentamientos fratricidas y a la falta de éxito en las empresas exteriores. En su opinión,

«Por lo que a España respecta, debemos considerar los diversos elementos etnológicos que la componen, muy lejanos aún de haberse fundido en un molde común; que las gentes del Norte se diferencian mucho de las del Mediodía» ${ }^{56}$.

Finalmente, la insolidaridad nacional no sólo se expresaba en la persistencia de diferencias étnicas, sino también en las desigualdades económicas, en los defectos de la administración, en el regionalismo y el independentismo, males que la última guerra de Cuba habría puesto de manifiesto de forma especialmente clara. Según Ovilo, el soldado español destinado en la isla había visto

«a los hijos renegar de la sangre de sus padres; a logreros, cuyos intereses defendía, no venderle lo más indispensable sin un ciento por ciento de beneficio; a falsos compatriotas cuya próxima defección adivinaba; a las exiguas soldadas que la Nación paga en metálico, convertidas en gran parte en papeles de mísero valor; a empleados venales y administradores corrompidos, no en tal número como se cree, pero sí en el suficiente para que agrandados por nuestros enemigos nos deshonraran ante el mundo entero» ${ }^{57}$.

En definitiva, tras la conmoción del 98, Ovilo se encontró de repente, como una suerte de personaje de Valle-Inclán frente a los espejos del callejón del Gato. Ante él, una visión esperpéntica de España similar a la que había proyectado sobre Marruecos en las décadas anteriores. El análisis de la situación española se podía hacer ahora en los mismos términos que el de la marroquí, de forma explícita, porque se había reducido aún más la distancia entre el Sultanato musulmán y la Monarquía católica; entre la corrupción de las respectivas administraciones y las carencias de ambos

55. Ovilo, Felipe. La decadencia del Ejército. Estudio de Higiene militar. Madrid: Librería de Fernando Fé; 1899, p. 11.

56. Ovilo, n. 55, p. 49.

57. Ovilo, n. 55, p. 62-63. 
ejércitos; entre las revueltas de los bereberes y las de los obreros; entre la fragmentación impulsada por los grandes caídes y por los regionalismos peninsulares; en suma, entre la decadencia de dos pueblos que, mucho tiempo atrás, habían sido gloriosos.

\section{Una trayectoria de reformismo sanitario entre España y Marruecos}

La visión de Ovilo sobre las relaciones hispano-marroquíes no sólo derivó de su análogo emplazamiento socio-político y geográfico en ambos países, sino también del hecho de que el médico segoviano desempeñara funciones similares en la sanidad española y en la marroquí. Señalaba Ovilo, con tono agridulce, que su segundo destino en Tánger en 1886 le había hecho «abandonar sin pena, un brillante destino, mis relaciones, mi familia, mis gustos» ${ }^{58}$. No obstante, pronto reprodujo en la ciudad del Estrecho su vida profesional madrileña, alcanzando un protagonismo en la sanidad marroquí quizás mayor, en términos relativos, del que había tenido en la española. Si como médico militar Ovilo había participado en la creación del Instituto Anatomopatológico de Sanidad Militar y en otras importantes iniciativas relacionadas con la higiene pública en el ejército, en Marruecos puso en marcha la Escuela de Medicina de Tánger (1886-1904 aprox.). Esta institución, creada por los gobiernos español y marroquí se encargó de proporcionar formación médica y quirúrgica a un cierto número de jóvenes marroquíes destinados al servicio de las unidades militares de estilo europeo (askar). Además de la enseñanza teórica, contaba con un dispensario anexo en el que los alumnos adquirían formación práctica a través de la asistencia clínica y quirúrgica gratuita a la población local ${ }^{59}$.

Ovilo, auxiliado por sus alumnos, prestó servicios de campaña a la sanidad militar marroquí, asistiendo a las fuerzas de la harka enviada para acabar con la sublevación de la cábila de Anyera en 1892, por lo cual recibió la felicitación del Sultán. Posteriormente, dos de aquellos estudiantes,

\footnotetext{
58. Ovilo, n. 11, p. 33.

59. Sobre la Escuela, ver López, José María. El P. José Lerchundi. Biografía documentada. Madrid: Imprenta Clásica Española; 1927; Ibn Azzuz Hakim, Mohammed. La sanidad española en Marruecos. Cuadernos de Estudios Africanos. 1953; 22: 33-50; Miège, n. 4; Lourido Díaz, Ramón. Las instituciones médico-sanitarias creadas por iniciativa del P. Lerchundi. Archivo Ibero-americano. 1996; 56 (223-224): 599-630.
} 
Mahboub al-Uazzani y Si Ahmed Temsamani, participarían como médicos militares en la expedición de 1898 contra los Bocoya ${ }^{60}$. En general, la labor de Ovilo en el ejército marroquí tuvo un carácter más médico que sanitario, y más acorde con las exigencias de un servicio de campaña que con las de uno «de paz». Pero Ovilo tenía claro que la formación de sus alumnos en la Escuela de Medicina debía orientarse hacia «las enfermedades más comunes que en Marruecos se presentan, como son las diversas formas de paludismo, oftalmias, afecciones sifilíticas y de la piel, de las vías urinarias, del estómago, etc., y gran número de heridas» ${ }^{61}$. Su labor docente y asistencial descansaba, por tanto, en una valoración general de la epidemiología marroquí que debía constituir la base de la estrategia médico-sanitaria para el ejército.

La labor sanitaria de Ovilo en Marruecos, como había sucedido anteriormente en la península, se extendió también al ámbito de la sanidad civil, esencialmente en relación con el Consejo Sanitario marítimo de Tánger o Consejo Sanitario Internacional de Marruecos ${ }^{62}$. Este organismo centralizado en Tánger y con delegaciones en los puertos marroquíes abiertos al comercio exterior (Tetuán, Larache, Rabat, Casablanca, Mazagán, Safi, Mogador) había obtenido en 1840 una delegación del Sultán Muley Abderrahman para asumir las competencias de sanidad marítima del país ${ }^{63}$. Tanto el Consejo como las delegaciones estaban integrados por los cónsules

60. Laredo, n. 24; Miège, n. 4, p. 219; Amster, Ellen Jean. Medicine and Sainthood: Islamic Science, French Colonialism and the Politics of Healing in Morocco, 1877-1935 [tesis doctoral]. University of Pennsylvania; 2003; Lourido Díaz, n. 59; Martínez Antonio, n. 7.

61. Escuela de Medicina y Dispensario español en Tánger. Reseña de su organización y trabajos. Informe del Dr. Felipe Ovilo y Canales al Ministro de Estado. Tánger, 31 de marzo de 1888. Archivo General de la Administración (en adelante AGA), Fondo Histórico de Marruecos (en adelante, FHM), Caja M-310.

62. Su papel en la sanidad civil peninsular estuvo relacionado, esencialmente, con la sanidad marítima. Entre otras cosas, Ovilo fue enviado en comisión por el Ministerio de la Gobernación a Francia en 1884 para estudiar la epidemia de cólera que había afectado a dicho país y fue nombrado representante español en la Conferencia Sanitaria Internacional de Roma de 1885. Para más detalles, ver Martínez Antonio, n. 7.

63. El Bezzaz, Mohammed. Le Conseil Sanitaire International du Maroc, 1792-1929 [tesis doctoral en árabe]. Université Mohammed V Rabat, 1994; Schepin, Oleg; Yermakov, Waldemar. International Quarantine. Madison: International Universities Press; 1991; Bonastra Tolós, Joaquim. Ciencia, sociedad y planificación territorial en la institución del lazareto [tesis doctoral]. Universidad de Barcelona, 2006; Martínez Antonio, Francisco Javier. Une liaison c(h)olérique? Les relations (sanitaires) franco-marocaines au milieu du XIXe siècle. In: Baduel, Pierre-Robert, ed. Chantiers et défis de la recherche sur le Maghreb contemporain. Paris: IRMC/Khartala; 2009. 
de todos los países extranjeros con representación oficial en el país, los cuales eran asesorados en materias técnicas por »médicos consultores». Ovilo actuó como tal en su primera estancia en Tánger, participando en la redacción de un nuevo reglamento cuarentenario en 1878 para hacer frente a la epidemia de cólera que asoló el país ${ }^{64}$. En su segunda etapa marroquí, Ovilo tuvo menos relación con el Consejo, especialmente con ocasión del cólera de 1895, en el que contribuyó decisivamente a establecer medidas preventivas para evitar la propagación de la epidemia ${ }^{65}$. Desde Tánger, Ovilo y los otros médicos adscritos a la Legación dirigían la acción médico-sanitaria en Marruecos a través de la supervisión de los «médicos consulares» que España había enviado a los principales puertos marroquíes desde mediados de la década de $1880^{66}$. Se trataba de médicos militares agregados a los consulados de los puertos, cuya doble función militar y civil incluía la asistencia gratuita a «moros pobres e israelitas». Según consignaba escuetamente el prestigioso higienista francés Louis Raynaud, «casi todos son al mismo tiempo médicos de la sanidad», lo que en la práctica quería decir que desempeñaban funciones relacionadas con la sanidad marítima en el marco de las delegaciones del Consejo Sanitario ${ }^{67}$.

En sus dos vertientes militar y marítima, la labor sanitaria de Ovilo en Marruecos se ajustó a los presupuestos generales de intervención amistosa o regeneración que defendía para la acción española en general. Un signo especialmente revelador de esta particular estrategia colonial fue que la Escuela de Tánger, a diferencia de lo afirmado por Jean-Louis Miège y otros historiadores, formara médicos y no practicantes o enfermeros, hecho inédito tanto en Marruecos, como en otros muchos ámbitos coloniales de la época ${ }^{68}$. Idealmente, Joaquín Costa había propuesto en 1884 que España

64. Raynaud, Louis. Étude sur I'hygiène et la médecine au Maroc. Alger: Leon; 1902, p. 65-66, 88; Laredo, n. 24, p. 172; Martínez Antonio, n. 7, p. 24.

65. Cuerpo de Sanidad militar. Hoja de servicios de D. Felipe Ovilo y Canales. Archivo General Militar de Segovia (en adelante AGMS), 1 a sección, O-25.

66. Larra Cerezo, Ángel de. Les Services sanitaires d'Espagne en Afrique. Madrid: Imprimerie du Dépôt de la Guerre; 1900, p. 9.

67. Raynaud, n. 64, p. 57.

68. Según Miège, «Al hospital que la Legación [de Tánger] hizo construir en 1888 fue, en efecto, agregada una escuela elemental que formaba, si no verdaderos médicos, sí al menos enfermeros indígenas y españoles». Miège, n. 4, 219. El caso más parecido a la iniciativa de Ovilo en Tánger fue el de la Escuela de Medicina de Argel, pero la mayoría de los escasos médicos árabes que se formaron en ella no ejercieron como tales sino como auxiliares y además en destinos periféricos. Quizás el ejemplo de Argel sirviera de inspiración para la iniciativa tan- 
fundara en Ceuta o en Fez instituciones de enseñanza científica superior, que incluyeran una «facultad de medicina que ahuyente poco a poco la turba de charlatanes y ensalmadores a quienes está hoy confiada la salud de los marroquíes» ${ }^{69}$. Ovilo ejecutó en la práctica lo más parecido a esta aspiración. Dadas las limitaciones y cautelas de la intervención española, la Escuela se emplazó en Tánger, se asoció a las necesidades del ejército y tuvo un carácter mixto, bajo los auspicios de la Reina regente y del Sultán. La instalación, el equipamiento, el plan de estudios y el personal técnico fueron responsabilidad española, mientras que el gobierno marroquí se encargó de estimular la llegada de alumnos y de darles «un modesto estipendio y un traje», como hacía en general con todos aquellos que iban a adquirir enseñanzas técnicas en Europa o eran formados por personal extranjero en Marruecos ${ }^{70}$.

Es cierto que Ovilo afirmaba en 1888 que la institución sólo proporcionaba «conocimientos médicos elementales y prácticos» y que, en consecuencia, los alumnos «asisten y curan como ayudantes del profesor $[\ldots]{ }^{71}$. Asimismo, en su informe sobre la Escuela, fechado en marzo de ese mismo año, comentaba respecto a dichos alumnos que "por lo menos son excelentes practicantes» ${ }^{72}$. Pero inmediatamente después, Ovilo llevó a sus tres primeros «discípulos» (Mustaphá ez-Zebdi, Hamed Romani y Mohammed Dukaly) a Madrid para que adquirieran «ciertos conocimientos prácticos indispensables a la profesión a que se dedican, con la visita a los Hospitales, Museos y cátedras de anatomía» y para que se examinaran en la Facultad de Medicina, donde obtuvieron «las mejores calificaciones» ${ }^{73}$. El Sultán visitó Tánger en 1889 y, tras conocer la Escuela, dio su aprobación a su labor; un año más tarde, tras recibir a Ovilo en Fez, dispuso que seis nuevos alumnos se incorporaran a la institución ${ }^{74}$. Uno de ellos, Si Ahmed

gerina. Gallois, William. Local Responses to French Medical Imperialism in Late-Nineteenth Century Algeria. Social History of Medicine. 2007; 20 (2): 315-331.

69. García Figueras, Tomás. La acción africana de España en torno al 98 (1860-1912). Vol. II, Madrid: CSIC; 1966, p. 124.

70. Despacho del Ministro de España en Tánger al Ministro de Estado. Tánger, 14 de octubre de 1899. AGA, FHM, Caja M-310.

71. Ovilo, n. 11, p. 33-34.

72. Ovilo, n. 61.

73. Memorial interno de la Sección de Administración del Ministerio de Estado sobre la Escuela de Medicina de Tánger. Madrid, 6 de octubre de 1895. AGA, FHM, Caja M-310; Fernández Rodríguez, n. 10, p. 242.

74. Fernández Rodríguez, n. 10, p. 263. 
Temsamani, afirmaría mucho tiempo después que había permanecido siete años en el centro ${ }^{75}$. A esto había que añadir la intensa labor práctica en el dispensario, donde, según estadísticas de Ovilo, se llegaron a asistir más de 500 enfermos sólo en los primeros ocho meses de 1887; así como la participación de algunos de los alumnos en las expediciones de castigo contra los Anyera y los Bocoya a lo largo de los años 90. Incluso Raynaud, poco dado en general a mostrar simpatía por las iniciativas españolas, afirmaba en 1902 que «se nos ha asegurado que tres de estos médicos, muy serios, están empleados en Tánger o en Marrakech para prestar asistencia a las tropas y ejercen provechosamente su oficio» ${ }^{76}$. Por tanto, a pesar de que no existió propiamente una facultad de medicina y de que sería necesario conocer con mayor detalle la trayectoria profesional de los alumnos de la Escuela en años posteriores, se podría decir que recibieron una formación relativamente completa y que asumieron responsabilidades técnicas dentro del ejército marroquí. El principal handicap de esta institución habría sido, en realidad, el reducido número de facultativos que consiguió formar.

En el ámbito de la sanidad marítima, la intervención española fue más directa, porque no se formó personal médico local para el servicio de los puertos como se hizo para el del ejército. Pero no por esto dejó de encuadrarse dicha intervención dentro del marco último de la «soberanía sanitaria» marroquí. Es difícil reconstruir el discurso de Ovilo sobre este asunto sin disponer de sus obras sobre la peregrinación marroquí y el cólera, publicadas en 1882 y 1895 y donde probablemente figuran sus reflexiones más extensas al respecto ${ }^{77}$. Sin embargo, la línea general de su actuación se reflejó en la red de médicos consulares bajo su supervisión, que constituyó una iniciativa aislada en comparación con las de otros países europeos en la sanidad marítima de Marruecos. A diferencia de éstos, la presencia oficial de médicos españoles tuvo que haber sido consensuada con el gobierno marroquí de forma más o menos explícita y, por ello, al precio de asumir en cierta medida la defensa de los intereses sanitarios locales. En este

75. Traduction d'une réclamation effectuée par Sidi Ahmed Temsamani, médecin en exercice à Fès, à S.E. le Grand Vizir. Note du Makhzen a ce sujet (arabe). Copie d'un acte d'autorité (arabe). Rabat, 19 septembre 1919. Centre des Archives Diplomatiques de Nantes, Fond Maroc, Carton 84, O XII 2.

76. Raynaud, n. 64, p. 60. La traducción es mía.

77. Estas obras, que aún no hemos podido localizar, son Hygiène internationale. De l'influence des pèlerinages marocains à la Mecque sur la propagation du choléra. Madrid: Tipografía de Manuel G. Hernández; 1882; El cólera en Tánger: Imprenta de A. J. Lúgaro; 1895. 
sentido, la actuación frente al cólera de 1895 constituyó el ejemplo más significativo del apoyo español a la sanidad marroquí. Ovilo y su compañero en la Legación, el Médico Mayor Severo Cenarro Cubero, dirigieron la lucha contra la epidemia en Tánger, éste último desde la Comisión de Higiene de la ciudad, de la que era presidente desde su fundación en 1888. A instancias de ambos, el Médico Mayor Enrique Rebolledo Laugier fue enviado a Mogador durante tres meses «con el fin de establecer un lazareto para evitar la importación del cólera en Marruecos por los peregrinos mahometanos, siendo Director de éste último $[\ldots] \gg{ }^{78}$. Finalmente, los distintos médicos consulares se encargaron de aplicar medidas de desinfección en sus respectivas ciudades de destino, como harían también en 1899 frente a la peste bubónica ${ }^{79}$.

\section{El discurso racial de Felipe Ovilo: la centralidad de los «moros»}

Para finalizar nuestro análisis, haremos una brevísima aproximación al discurso científico-médico del doctor Ovilo sobre los marroquíes. Como sucedía con su visión de las relaciones entre España y Marruecos y de la sociedad marroquí, dicho discurso adoptó una particular formulación, condicionada por la analogía en la posición social, institucional y geográfica en ambos países que hemos señalado en los dos apartados anteriores. En concreto, nos parece decisivo el hecho de que el concepto de raza, presente a lo largo y ancho de sus publicaciones, no se tradujera en la definición de una «patología marroquí». Por un lado, su discurso racial careció de una base científica comparable a sus reflexiones sobre el cólera y otras epidemias o sobre la higiene pública. Por otro lado, Ovilo reconoció la amplia heterogeneidad racial existente en el Imperio Xerifiano. Sin embargo, el factor fundamental que le impidió postular la existencia de una «raza marroquí» y de ciertas enfermedades y hábitos patológicos específicos de la misma fue la proximidad racial que percibía entre la población de España y Marruecos. En su opinión,

78. Cuerpo de Sanidad militar. Hoja de servicios de Don Enrique Rebolledo Laugier. AGMS, $1^{\text {a }}$ Sección.

79. Cuerpo de Sanidad militar. Hoja de servicios de Don Francisco Triviño Valdivia. AGMS, 1 a sección. 
«hay tipos que recuerdan tan a lo vivo al español, o hay en España tantos que a ellos se asemejan, que bastaría una simple mirada para adivinar que es la misma raza que pobló nuestras más ricas provincias, si datos históricos, etnográficos y antropológicos no lo afirmaran de un modo concluyente, y que aleja del ánimo toda duda» ${ }^{80}$.

En contraste con los discursos raciales de la Argelia francesa, basados en la dicotomía reduccionista entre árabes y bereberes y en la diferencia radical de ambas razas respecto a la población metropolitana, la visión de Ovilo sobre Marruecos se basaba en la centralidad dada a los «moros», concebidos al mismo tiempo como un embrión de «raza marroquí» y como un vínculo, históricamente identificable, con la «raza española» ${ }^{81}$. Respecto a lo primero, el peso decisivo de los «moros» dentro de la sociedad marroquí se reflejaba en que eran «los verdaderos amos de Marruecos», la parte «más instruida, rica y poderosa del Mogreb» ${ }^{82}$. Respecto a lo segundo, Ovilo afirmaba que los «moros» eran «los descendientes de los mauritanos, mezclados con los fenicios, sirios, greco-romanos, vándalos, árabes, españoles y negros», una raza «mezclada» que sólo se diferenciaba de la española porque ésta última había contribuido a su formación a través de las diversas expulsiones de «moros andaluces» (especialmente granadinos) y moriscos ${ }^{83}$. De esta forma, la superioridad racial de los españoles sobre los marroquíes era para Ovilo bastante relativa y sólo residía en la dependencia respecto a los aportes peninsulares y en la incapacidad para actuar como crisol de las diversas variedades étnicas dando así lugar a una «raza marroquí» propiamente dicha.

Por todo ello, ni existía en la obra de Ovilo un estereotipo unitario del marroquí, ni las tentativas de patologización de los distintos tipos de «moros» y de resto de grupos raciales se formularon preferentemente en términos biológicos, sino históricos, sociales y morales. Sirva como ejemplo

80. Ovilo, n. 11, p. 4.

81. Sobre el discurso de los médicos franceses en Argelia, ver Lorcin, Patricia M.E. Imperial Identities. Stereotyping, Prejudice and Race in Colonial Algeria. London-New York: I.B. Tauris; 1995; Lorcin, Patricia M. E. Imperialism, Colonial Identity and Race in Algeria, 1830-1870. The Role of the French Medical Corps. Isis. 1999; 90: 653-679. Junto al discurso sobre los «moros» existió uno sobre los «judíos» que también tuvo gran importancia para Ovilo a la hora de argumentar las semejanzas entre españoles y marroquíes. No obstante, por razones de espacio, no podemos referirnos a él en este trabajo.

82. Ovilo, n. 11, p. 61-62.

83. Ovilo, n. 9, p. 58. 
de ambas cosas la distinción de Ovilo entre los «moros de las ciudades» o «moros andaluces» y los «moros del campo» y su descripción de ambos grupos. Los «moros del campo» parecían «tener su origen en la unión del árabe y el bereber, de los que tienen muchos caracteres anatómicos» ${ }^{84}$. En su opinión, eran «los seres más desdichados de Marruecos» ya que «viven pobres y explotados por los moros de la ciudad, por el Gobierno y, sobre todo, por sus autoridades locales» ${ }^{85}$. Eran «fanáticos en religión», fatalistas ante la muerte, a la que veían llegar «sin temor, y hasta con placer» y sufridos ante los tormentos y penalidades ${ }^{86}$. Respecto a los «moros de las ciudades», eran la parte «más viciosa y corrompida [del Mogreb]; tienen todos nuestros defectos y los de los árabes, sin que estén compensados por las buenas cualidades de sus progenitores» ${ }^{87}$. En el ámbito psicológico, a pesar de las escasas excepciones de los «que son un modelo de hidalguía y caballerosidad, como aquellos ilustres granadinos», tenían el defecto principal de la hipocresía, "porque con ella ocultan a primera vista los demás» ${ }^{88}$. Una hipocresía que les hacía mostrar afectación religiosa sin rechazar «una botella de Champagne o un negocio oscuro»; que les daba un aspecto respetable que escondía la «ligereza» de su palabra y su ignorancia; que les hacía mostrar «circunspección, prudencia, humildad, respeto» con el fuerte e «insolencia, soberbia, despotismo» con el «desheredado» ${ }^{89}$. Respecto a su físico, Ovilo consideraba que estos «moros» eran «de mediana estatura; cuando jóvenes, bien formados; más tarde, por la ociosidad y el género de vida sedentario, se hacen obesos $[\ldots]{ }^{90}$. No obstante, también afirmaba que «su fisonomía es grave, no exenta de agrado; el color blanco; los ojos [...] son negros y vivos; la cara redonda o ancha, y, en general, su constitución es buena» ${ }^{91}$.

Ovilo resumía su exposición general sobre los «moros» marroquíes con la siguiente reflexión:

\footnotetext{
84. Ovilo, n. 9, p. 59

85. Ovilo, n. 9, p. 59

86. Ovilo, n. 9, p. 59

87. Ovilo, n. 9, p. 61

88. Ovilo, n. 9, p. 61

89. Ovilo, n. 9, p. 61

90. Ovilo, n. 9, p. 63

91. Ovilo, n. 9, p. 63.
} 
«A pesar de los muchos vicios de que adolecen, yo no me atrevería a condenarlos en absoluto; la décima parte de sus faltas, podrá reconocer por origen su natural condición; pero las otras nueve son debidas a la funesta organización y el absurdo gobierno que les oprime» ${ }^{92}$.

\section{Conclusión}

La visión de Felipe Ovilo Canales sobre Marruecos y su actuación en el país vecino constituyeron un ejemplo representativo de los importantes esfuerzos de la España de la Restauración por aumentar su influencia al otro lado del Estrecho, esfuerzos que quedarían drásticamente truncados después del desastre del 98. A través de la trayectoria profesional y del discurso político y científico de Ovilo hemos querido profundizar en una coyuntura histórica en la que Marruecos se convirtió en horizonte factible del colonialismo español, aunque desapareciera rápidamente como tal a consecuencia de la pérdida de Cuba, Filipinas y Puerto Rico. En nuestra opinión, el particular carácter de dicho colonialismo se reflejó en el trasfondo regeneracionista de la visión social y política de Ovilo sobre Marruecos, en su labor como reformista sanitario en la Escuela de Medicina y en el Consejo Sanitario de Tánger y, finalmente, en la raíz predominantemente histórica y moral de su discurso racial sobre los «moros». La actuación y la mirada de Ovilo descansaron en la percepción de una confluencia hispano-marroquí que, en último término, permitía adivinar «una misma raza» a ambos lados del Estrecho. Por ello, sin ser una mirada de igualdad, sí que constituyó al menos una visión relativamente respetuosa de Marruecos, fruto tanto de las limitaciones internas e internacionales de España en comparación con otros países europeos, como del relativo desarrollo del vecino magrebí en comparación con otras sociedades no europeas que compartían con él la común amenaza del colonialismo.

92. Ovilo, n. 9, p. 63. La visión de Ovilo sobre los «moros» forma parte de una larguísima trayectoria de discursos escritos y representaciones iconográficas sobre marroquíes y musulmanes en España. Nuestro análisis deja a un lado, no obstante, los problemas de aquel término, cuyo sentido ha sido múltiple y ha variado considerablemente según el periodo histórico. Sobre ambas cuestiones, ver Mateo Dieste, Josep Lluís. El «moro» entre los primitivos: el caso del Protectorado español en Marruecos. Barcelona: Fundación La Caixa; 1997; Martín Corrales, Eloy. La imagen del magrebí en España. Una perspectiva histórica. Siglos XVI-XX. Barcelona: Bellaterra; 2002; Dossier «Imágenes coloniales de Marruecos en España». Melanges de la Casa de Velásquez. 2007; 37 (1): 7-154. 


\section{Agradecimientos}

Quiero agradecer a la investigadora Irene González y al Prof. Youssef Akmir sus útiles comentarios y a los referees sus sugerencias, que han ayudado a mejorar este artículo. 